\title{
Revisiting the Role of Chronic Kidney Disease and Its Association With Anemia in Diabetics and Non-Diabetics: A Cross Sectional Audit of 450 Cases
}

\author{
Lavanya Rajagopal ${ }^{1 *}$, Sundaram Arunachalam ${ }^{1}$, Shivashekar Ganapathy ${ }^{1}$, Balaji Ramraj ${ }^{2}$ and Veena Raja $^{1}$ \\ ${ }^{1}$ Department of Pathology, SRM Medical College Hospital and Research Centre, Kattankulathur, Chennai (India) \\ ${ }^{2}$ Department of community medicine, SRM Medical College Hospital and Research Centre, Kattankulathur, Chennai (India)
}

\begin{abstract}
Background: Anemia is twice common in diabetics compared with non-diabetics. The etiopathogenesis of anemia in diabetes is multifactorial [Chronic Kidney Disease (CKD), Iron Deficiency Anemia (IDA), B12 and folate deficiency, etc]. Anemia in diabetic patients prior to the evidence of renal impairment is rarely reported.
\end{abstract}

Objective: To determine the role of CKD and other etiological factors of anemia in diabetics and non-diabetics. To correlate the degree of anemia with severity of CKD and glycemic status.

Methods: A cross-sectional study carried out in SRM Hospital and Research Centre, Chennai. Total 450 subjects (150 controlled \& 150 poorly controlled diabetics, 150 non-diabetics) with equal number of anemic and not-anemic patients in each group were included. Further categorized into those with CKD and without CKD.

Results: In our study, only $33 \%$ anemic patients with diabetes had low eGFR and CKD $(\mathrm{p}<0.05)$. Among the rest $67 \%$ majority of anemia in diabetics was due to IDA which became evident from low iron profile and microcytic blood picture. As CKD progressed, anemia worsened. Moreover poorly controlled diabetics with CKD showed statistical significant difference between anemic and not-anemic patients. Anemia was highly prevalent in females and CKD in males in both diabetics and non-diabetics.

Conclusion: In this study we insist on the utter importance of evaluating other etiological factors apart from CKD such as IDA for accurate diagnosis, treatment of anemia in diabetics and thereby preventing the prognosis of complications.

Keywords: Chronic Kidney Disease, Anemia, Diabetes, Iron Deficiency Anemia.

\section{Introduction}

Anemia is twice common in diabetics compared with non-diabetics. ${ }^{[1]}$ The etiopathogenesis of anemia in diabetes is multifactorial which includes deficiency in erythropoietin (EPO) synthesis and release due to Chronic Kidney Disease (CKD), nutritional deficiency (iron, vitamin $\mathrm{B}_{12}$ ), systemic inflammation, concomitant autoimmune diseases, drugs (ACE inhibitors) and hormonal changes. ${ }^{[2]}$ Anemia potentially contributes to the development and progression of diabetic micro and macro vascular complications such as diabetic kidney disease, retinopathy, neuropathy etc. Despite these facts, anemia is still unrecognized in $25 \%$ of diabetic patients. ${ }^{[3]}$ Anemia occurs earlier and more severe in CKD in Diabetes Mellitus (DM) than in patients with renal impairment from other causesand is associated with more rapid decline in Glomerular Filtration Rate (GFR) ${ }^{[4]}$.Probably this may be due to EPO deficiency and hypo responsiveness to the action of EPO. ${ }^{[4,5]} \mathrm{Al}$ Khowry et aldemonstrated that for each CKD stage, hemoglobin is $1 \mathrm{~g} / \mathrm{dl}$ lower in diabetics than non-diabetics. ${ }^{[6]}$ But some recent studies have linked anemia with relatively low serum EPO in persons with either type 1 or type 2 diabetes, even without advanced kidney disease or overt uremia. ${ }^{[7-10]}$ While limited studies have reported the incidence of anemia in diabetic patients prior to the evidence of renal impairment. ${ }^{[9]}$ To shed additional light on this dispute, we aimed in this study to determine the role of chronic kidney disease and its association with anemia in diabetics and non-diabetics. Additionally we correlated the degree of anemia with severity of CKD and glycemic status in these patients.

\section{Materials and Methods}

This is a cross-sectional study carried out in SRM Medical College Hospital and Research Centre, Chennai, Tamil Nadu between February 2016 to October 2016 after obtaining approval from our institutional ethical committee. All diabetic (Type $2 \mathrm{DM}$ ) and non-diabetic patients from both outpatient and inpatient departments of our hospital 
were included in this study evaluation. Detailed medical history was recorded. An informed consent was obtained from all the study subjects

Total450 subjects were divided into three groups which included 150known diabetics with controlled Fasting plasma glucose [FPG] level $\leq 126 \mathrm{mg} / \mathrm{dl}$ since last 6 months, 150 poorly controlled diabetics (FPG $>126 \mathrm{mg}$ / dl since last 6 months), 150 non-diabetics (no history of $\mathrm{DM}$ and two $\mathrm{FPG}<126 \mathrm{mg} / \mathrm{dl}$, performed close to the date of the complete blood count)with equal number of anemic and not-anemic patients in each group.

Based on the data observed among our study subjects we categorized them into those with CKD (78 diabetics and 37 non-diabetics) and without CKD (222 diabetics and 113 non-diabetics). Among 78 diabetic CKD patients 50 had anemia and 28 without anemia. Out of 222 diabetic without CKD, 100 had anemia and 122 were without anemia. Among 37 non-diabetic CKD patients, 23 had anemia and 14were without anemia. Out of 113nondiabetic non-CKD patients, 52 had anemia and 61 were without anemia. [Fig-1]

Anemia: The anemic patients were selected based on their hemoglobin levels $(\mathrm{Hb}<13 \mathrm{gm} \%$ in males and $<12 \mathrm{gm} \%$ in females) based on definition of World Health Organization (WHO) ${ }^{[11]}$ Anemic patients were further categorized as mild anemia (male 12-12.9 gm/dl and female 11-11.9gm/ $\mathrm{dl}$ ), moderate anemia (male 9-11.9 gm/dl and female 8-10.9 $\mathrm{gm} / \mathrm{dl}$ ) and severe anemia (male $<9 \mathrm{gm} / \mathrm{dl}$ and female $<8$ $\mathrm{gm} / \mathrm{dl})$. Anemia was defined as normocytic with a mean corpuscular volume (MCV) of 80 to $100 \mathrm{fl}$, microcytic with the $\mathrm{MCV}<80 \mathrm{fl}$ and macrocytic with the MCV $>100$ ff. ${ }^{[12]}$

Chronic Kidney Disease: The estimated glomerular filtration rate (eGFR) was calculated using the Modification of Diet in Renal Disease (MDRD)formula which is recommended by the Japanese Society of Nephrology:

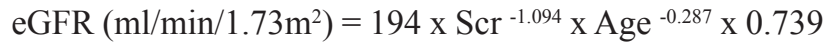
(if female). The stages of CKD were based on the National Kidney Foundation Kidney Disease Outcomes Quality Initiative (NKF K/DOQI) clinical practice guidelines. Patients were classified based on eGFR in both diabetics and non-diabetics. eGFR values $\geq 90$ (CKD1), 60-89 (CKD2), 30-59 (CKD3), 15-29 (CKD4) and <15 (CKD5) $\mathrm{ml} / \mathrm{min} / 1.73 \mathrm{~m}^{2} \cdot{ }^{[12-14]}$

Measurements: Fasting plasma glucose (FPG) estimated by glucose oxidase/peroxidase method. Hemoglobin $(\mathrm{Hb})$, Mean corpuscular volume (MCV) was estimated by sysmex XT-1800 analyzer. Serum creatinine was estimated by Jaffe's kinetic method.HbA $\mathrm{C}_{1}$ was measured by HPLC method using Bio-Rad analyzer.
Statistical analysis: The data were analyzed using SPSS version 21.All the categorical variables were analyzed using chi square test. Continuous variables were presented as mean \pm S.D. Numerical variables werecompared using independent sample t-test. $\mathrm{P}$ value $<0.05$ was considered statistically significant.

\section{Results}

Anemia: Our study result showsa high incidence of anemia in females $(62 \%)$ when compared with males $(38 \%)$ in both diabetics and non-diabetics and was statistically significant $(\mathrm{p}<0.05)$ [Table-1]

Among 150 out of 300 diabetics with anemia, only 50 patients showed low eGFR $\left(<90 \mathrm{ml} / \mathrm{min} / 1.73 \mathrm{~m}^{2}\right)$ which may be possibly due to CKD and rest 100 cases showed high eGFR $\left(\geq 90 \mathrm{ml} / \mathrm{min} / 1.73 \mathrm{~m}^{2}\right)$ indicating normal renal function which was statistically significant $(\mathrm{p}<0.05)$. Among 75 out of 150 non- diabetics with anemia, only 23 showed low eGFR possibly due to CKD and rest 52 cases showed high eGFR indicating normal renal function which was statistically in-significant ( $p>0.05)$. [Table-2]

Chronic kidney disease: In our study, CKD was more prevalent in males (62\%) than females (38\%) [Table-3/ Fig-2].In poorly controlled diabetic patients with CKD, statistical significant difference was observed between anemic and not-anemic patients $(\mathrm{p}<0.05)$ but however in case of controlled diabetics with CKD there was no significant difference between anemic and not-anemic patients $(\mathrm{p}>0.05)$.

In case of non-diabetics with CKD, no statistical significant difference was observed between anemic and not-anemic patients $(\mathrm{p}>0.05)$. Mean $\mathrm{HbA}_{1} \mathrm{C}$ between CKD (7.98 $\pm 0.21)$ and non-CKD $(7.58 \pm 0.13)$ patients was not statistically significant in both diabetics and non-diabetics $(\mathrm{p}>0.05)$ [Table-4].

Correlation between stages of CKD with severity of anemia: Majority (54.3\%) of non-anemic patients were found in CKD stage 1. Also majority of patients with severe anemia $(57.1 \%)$ were found in CKD stage 5. This implies that as CKD progresses, severity of anemia worsens. [Table-5]

Anemia subtypes in CKD: Among patients having CKD with anemia in our study, we observed normocytic blood picture in only $34 \%$ of diabetics and $26 \%$ of non-diabetics. Majority showed microcytic with iron deficiency $(56 \%$ in diabetics and $56.5 \%$ in non-diabetics) and few showed macrocytic with vitamin $\mathrm{B}_{12}$ deficiency $(10 \%$ in diabetics and $17.3 \%$ in non-diabetics) which was later confirmed with serum iron and $\mathrm{B}_{12}$ assay. [Table-6] 
Table 1: Gender wise stratification of anemia in diabetic and non-diabetic subjects.

\begin{tabular}{|c|c|c|c|c|c|c|c|c|}
\hline \multirow{3}{*}{ Particulars } & \multirow[t]{3}{*}{ Total } & \multicolumn{5}{|c|}{ Anemia } & \multirow{3}{*}{ Chi square } & \multirow{3}{*}{$p$ value } \\
\hline & & \multicolumn{2}{|c|}{ Yes $(n=225)$} & \multicolumn{2}{|c|}{ No (225) } & & & \\
\hline & & $\mathrm{n}$ & $\%$ & $\mathrm{n}$ & $\%$ & & & \\
\hline Male & & 228 & 87 & $38 \%$ & 141 & $62 \%$ & 25.92 & 0.0001 \\
\hline Female & & 222 & 138 & $62 \%$ & 84 & $38 \%$ & & \\
\hline
\end{tabular}

Table 2: Prevalence of anemia and chronic kidney disease in diabetic and non-diabetic subjects.

\begin{tabular}{|c|c|c|c|c|c|c|c|}
\hline \multirow{3}{*}{ Particulars } & \multirow{3}{*}{ Total } & \multicolumn{4}{|c|}{ CKD } & \multirow{3}{*}{ Chi square } & \multirow{3}{*}{$p$ value } \\
\hline & & \multicolumn{2}{|c|}{ Yes } & \multicolumn{2}{|c|}{ No } & & \\
\hline & & $\mathbf{n}$ & $\%$ & $\mathrm{n}$ & $\%$ & & \\
\hline DM with anemia & 150 & 50 & $33 \%$ & 100 & $67 \%$ & \multirow{2}{*}{8.385} & \multirow{2}{*}{0.003} \\
\hline DM without anemia & 150 & 28 & $19 \%$ & 122 & $81 \%$ & & \\
\hline Non DM with anemia & 75 & 23 & $31 \%$ & 52 & $69 \%$ & \multirow{2}{*}{2.906} & \multirow{2}{*}{0.088} \\
\hline Non DM without anemia & 75 & 14 & $19 \%$ & 61 & $81 \%$ & & \\
\hline
\end{tabular}

Table 3:Gender wise stratification of chronic kidney disease in diabetic and non-diabetic subjects.

\begin{tabular}{|c|c|c|c|c|c|c|c|c|}
\hline \multirow{3}{*}{ Particulars } & \multirow[t]{3}{*}{ Total } & & \multicolumn{4}{|c|}{ CKD } & \multirow{3}{*}{ Chi square } & \multirow{3}{*}{$p$ value } \\
\hline & & \multicolumn{2}{|c|}{ Yes $(n=115)$} & \multicolumn{2}{|c|}{ No(n=335) } & & & \\
\hline & & $n$ & $\%$ & $\mathbf{n}$ & $\%$ & & & \\
\hline Male & & 228 & 71 & $31 \%$ & 157 & $69 \%$ & \multirow[t]{2}{*}{7.58} & \multirow[t]{2}{*}{0.005} \\
\hline Female & & 222 & 44 & $20 \%$ & 178 & $80 \%$ & & \\
\hline
\end{tabular}

Table 4: Association between anemia, chronic kidney disease and glycemic status.

\begin{tabular}{|c|c|c|c|c|c|}
\hline \multirow{2}{*}{\multicolumn{2}{|c|}{ Particulars Yes $(n=115)$}} & \multicolumn{2}{|c|}{ CKD } & \multirow{2}{*}{ Chi square } & \multirow{2}{*}{$p$ value } \\
\hline & & \multirow{2}{*}{$\begin{array}{c}\text { No }(n=335) \\
27\end{array}$} & \multirow[b]{2}{*}{48} & & \\
\hline \multirow{2}{*}{ Controlled DM } & With anemia & & & \multirow{2}{*}{2.57} & \multirow{2}{*}{0.109} \\
\hline & Without anemia & 18 & 57 & & \\
\hline \multirow{2}{*}{ Poorly controlled DM } & With anemia & 23 & 52 & \multirow{2}{*}{6.57} & \multirow{2}{*}{0.01} \\
\hline & Without anemia & 10 & 65 & & \\
\hline \multirow{2}{*}{ Non DM } & With anemia & 23 & 52 & \multirow[b]{2}{*}{2.91} & \multirow[b]{2}{*}{0.088} \\
\hline & Without anemia & 14 & 61 & & \\
\hline \multicolumn{2}{|l|}{ Mean Hba1c } & $7.98 \pm 0.21$ & $7.58 \pm 0.13$ & $T$ test -1.620 & 0.106 \\
\hline
\end{tabular}

Table 5: Correlation between stages of chronic kidney disease with severity of anemia in diabetics and non-diabetics.

\begin{tabular}{|c|c|c|c|c|c|c|c|c|c|}
\hline \multirow{2}{*}{ CKD Stages } & \multirow{2}{*}{ Total } & \multicolumn{2}{|c|}{ No anemia $(n=225)$} & \multicolumn{2}{|c|}{ Mild anemia $(n=98)$} & \multicolumn{2}{|c|}{ Moderate anemia $(n=97)$} & \multicolumn{2}{|c|}{ Severe anemia $(n=30)$} \\
\hline & & $\mathbf{n}$ & $\%$ & $\mathbf{n}$ & $\%$ & $\mathbf{n}$ & $\%$ & $n$ & $\%$ \\
\hline CKD 1 & 334 & 182 & 54.3 & 73 & 21.8 & 62 & 18.5 & 17 & 5.1 \\
\hline CKD 2 & 45 & 18 & 40.0 & 13 & 28.9 & 13 & 28.9 & 1 & 2.2 \\
\hline CKD 3 & 56 & 23 & 41.1 & 10 & 17.9 & 18 & 32.1 & 5 & 8.9 \\
\hline CKD 4 & 8 & 2 & 25.0 & 1 & 12.5 & 2 & 25.0 & 3 & 37.5 \\
\hline CKD 5 & 7 & 0 & - & 1 & 14.3 & 2 & 28.6 & 4 & 57.1 \\
\hline
\end{tabular}

Chi square - 55.541, P value - 0.0001

Table 6: Anemia subtypes in chronic kidney disease.

\begin{tabular}{|c|c|c|c|c|}
\hline Anemia & Diabetic CKD & Non diabetic CKD & Chi square & $P$ value \\
\hline Microcytic & 28 & 13 & \multirow{4}{*}{1.01} & \multirow{4}{*}{0.602} \\
\hline Normocytic & 17 & 6 & & \\
\hline Macrocytic & 5 & 4 & & \\
\hline Total & 50 & 23 & & \\
\hline
\end{tabular}




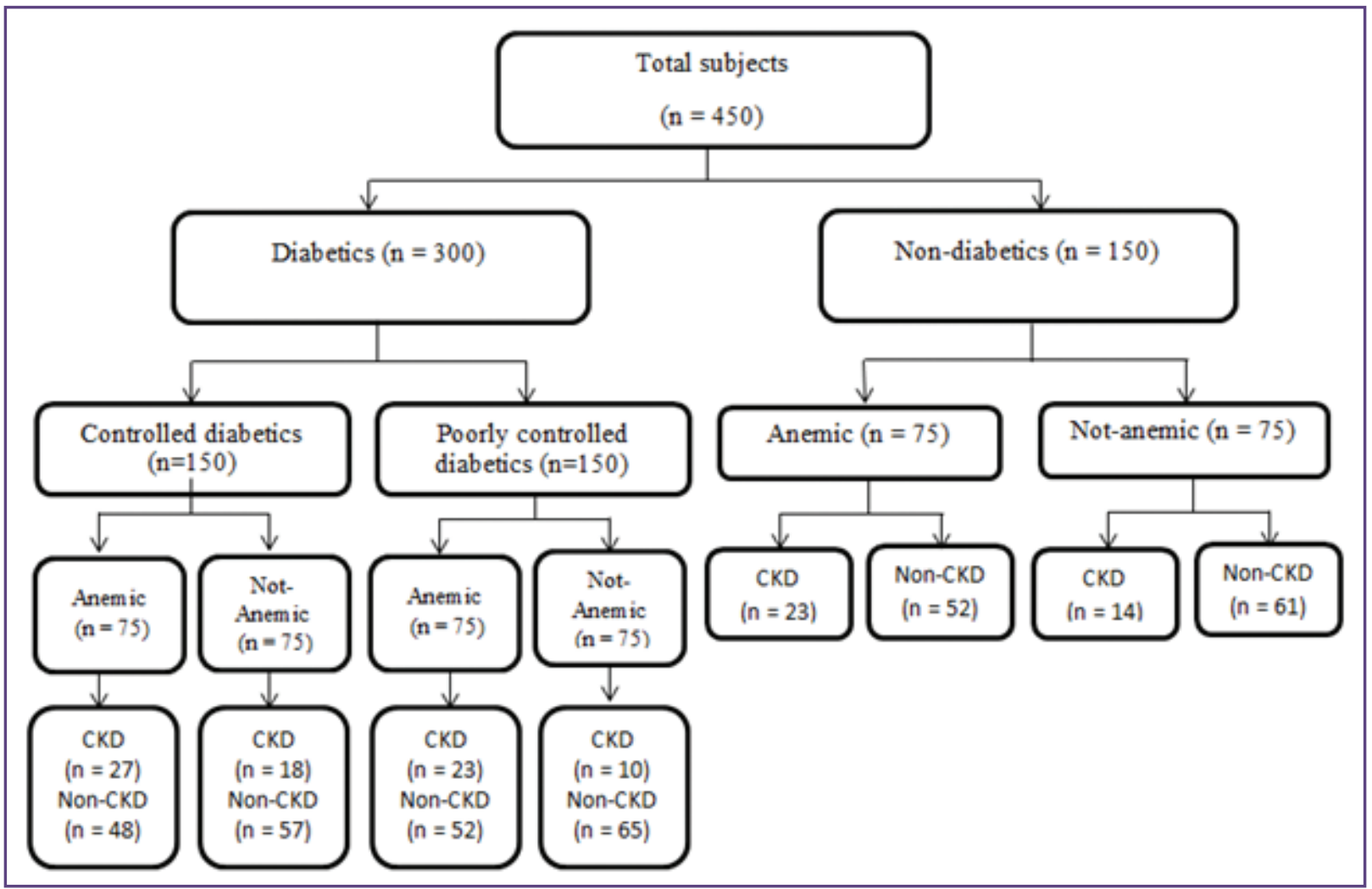

Fig. 1: Schematic representation of selection of cases.

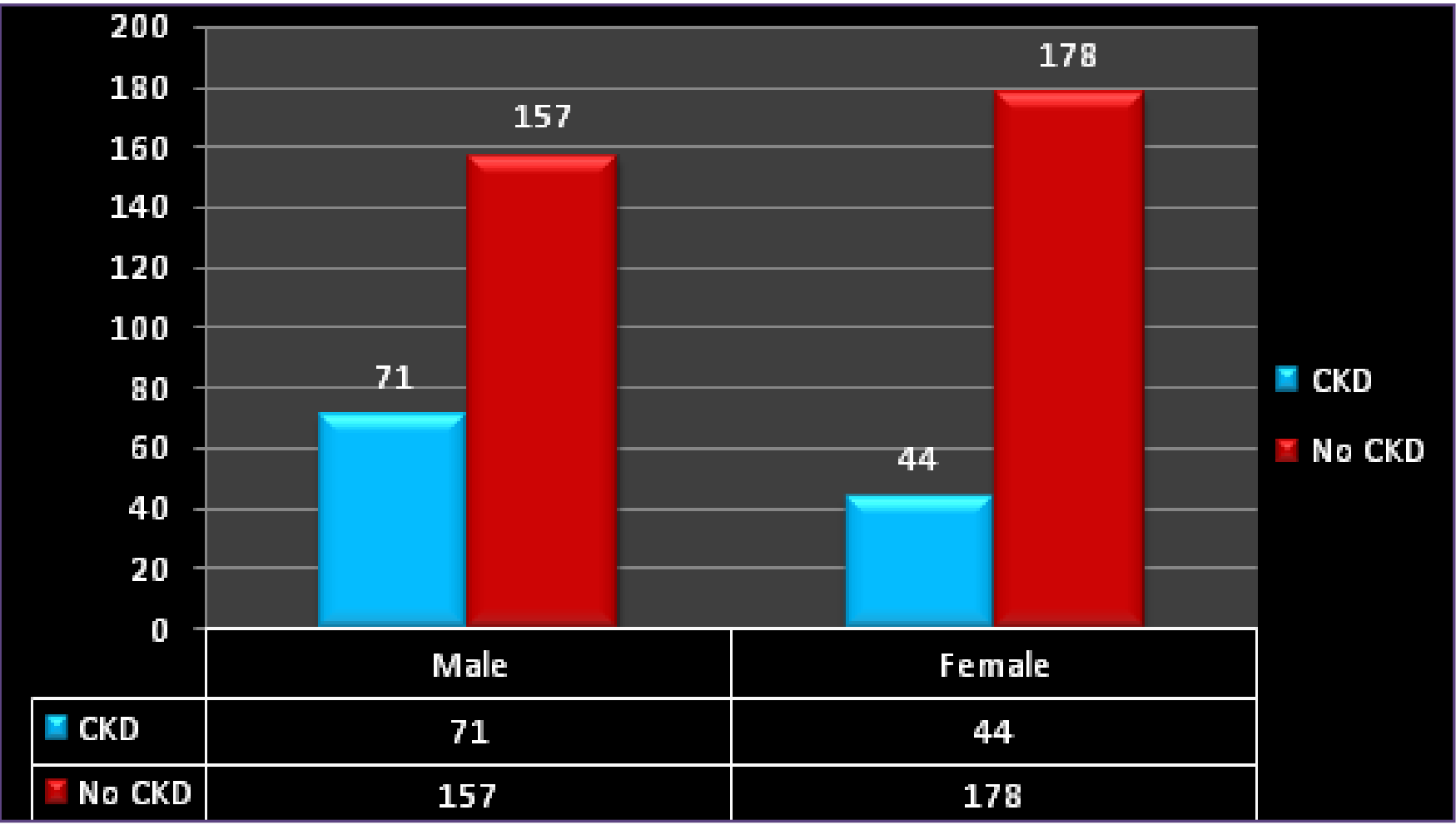

Fig-2: Gender wise stratification of chronic kidney disease in diabetic and non-diabetic subjects. 


\section{Discussion}

Even thoughit's a well-known fact that anemia is a common accompaniment to diabetes leading to its various complications, diabetics are rarely evaluated and treated for anemia. ${ }^{[3]}$ While several reports have indicated that anemia mostly occurs in diabetic patients with renal insufficiency,some studies have also reported anemia without renal dysfunction. ${ }^{[7,9]}$ But in our study, only $33 \%$ of diabetic patients with anemia had CKD having low eGFR $\left(<90 \mathrm{~mL} / \mathrm{min} / 1.73 \mathrm{~m}^{2}\right)$. This contrasts with the commonly presumed fact that CKD is the usual cause of anemia in diabetes. Hence some other factors could have influenced the occurrence of anemia in these diabetic patients.

The main cause of anemia in CKD may be EPO deficiency due to reduction in the number of specific EPO synthesizing interstitial cells, disruption of interstitial anatomy or vascular architecture of kidney. ${ }^{[16,17]} \mathrm{Few}$ other studies also proposed that hypo responsiveness to the action of EPO may be due to renal denervation in diabetic autonomic neuropathy reducing splanchnic sympathetic stimulation of EPO production. ${ }^{[8,9,18]}$

Apart from CKD, anemia in diabetes may be due to other cause such as nutritional deficiency (iron, vitamin B12 and folate), systemic inflammation, concomitant autoimmune disease, drugs(ACE inhibitors) and hormonal changes. We observed in both diabetics and non-diabetics that anemia was more prevalent in females $62 \%$ thanmales $38 \%$ and was statistically significant $(\mathrm{p}<0.05)$. This implies that anemia is influenced by gender in both these groups which correlates with the study results of Cawood et al. ${ }^{[19]}$ Ourresult contradicts with the study result of Craig et al who reported that anemia is common in males. ${ }^{[20]}$ In this study with reference to age, in subjects $<60$ years, anemia was more prevalent in females and in subjects $>60$ years anemia was common in males. ${ }^{[1]}$

Data from our study show CKD with anemia was more common in males (55\%) than females $(45 \%)$ in both diabetics and non-diabetics and was statistically significant $(\mathrm{p}<0.05)$. The possible pathogenesis for this male preponderance of anemia in kidney dysfunction is due to decreased lutenizing hormone production and decreased prolactin clearance lowering the androgen levels. Androgens stimulate erythropoiesis by increasing erythropoietin production and by direct augmentation of marrow stem cells. ${ }^{[22]}$ Finally, CKD has been associated with reduced testosterone levels in men. ${ }^{[23]}$ On the other hand, premenopausal and postmenopausal women with diabetes have higher bioavailable testosterone level. ${ }^{[24]}$

Regardless of the positive and significant relationship between $\mathrm{HbA}_{1} \mathrm{C}$ and $\mathrm{CKD}$ observed in other studies of
Inaba $\mathrm{M}$ et al, Chujo $\mathrm{K}$ et al, Riveline JP et al, our study result doesn't show a significant relationship between $\mathrm{HbA}_{1} \mathrm{C}$ and $\mathrm{CKD}$ in both diabetics and non-diabetics ${ }^{[25,26,27]}$. This result of ours goes in hand with the study results of Vos FE et al. ${ }^{[28]}$

Comparison of CKD with Anemia: CKD contributed to only $33 \%$ of anemia in diabetics and $31 \%$ in non-diabetics, hence causes other than CKD would have contributed to anemia in these patients. This figure is almost same as compared to the prevalence of $25 \%$ documented by Janmohamed et al. ${ }^{[17]}$ Out of 115 patients with CKD, majority of patients $(64 \%)$ were anemic and rest (36\%)were not-anemic. This implies that anemia is not always due to CKD but other factors like nutritional deficiency (iron, B12, folic acid), hormones etc may play a role. Among patients having CKD with anemia in our study, we observed normocytic blood picture in only $34 \%$ of diabetics and $26 \%$ of non-diabetics. Majority showed microcytic blood picture with iron deficiency $(56 \%$ in diabetics and $56.5 \%$ in non-diabetics) and few showed macrocytic blood picture with vitamin B12 deficiency (10\% in diabetics and $17.3 \%$ in non-diabetics). [Table-6].

Iron deficiency was found in among $56 \%$ of diabetics with anemia, which is higher than the figure of $15.5 \%$ reported by Sharif et al. ${ }^{[18]}$ However, Katherine et al found iron deficiency in none of their diabetic patients in a study conducted in UK. ${ }^{[19]}$ Higher prevalence of iron deficiency in these diabetics may be due to lower socioeconomic class who frequently has nutritional deficiencies particularly iron deficiency which is common in Asian countries, lack of awareness and inability to access appropriate healthcare due to financial constraints. ${ }^{[20]}$

Hyperglycemia has a direct relationship with the development of an inflammatory condition showed by the increased expression of pro-inflammatory cytokines such as IL-6, TNF- $\alpha$, and NFkB. Thus, diabetes, as well as hyperglycemia due to its nature, is also an inflammatory disease character. Studies show that the longer the duration of the disease and/or loss of glycemic control, the higher the inflammatory process. ${ }^{[7,8]}$

The elevation of pro-inflammatory cytokines plays an essential role in insulin resistance and induces the appearance of diabetic micro and macrovascular complications like, kidney disease, cardiovascular disease and anemia. By increasing especially IL-6, antierythropoietic effect occurs, since this cytokine changes the sensitivity of progenitors to erythropoietin (erythroid growth factor) and also promotes apoptosis of immature erythrocytes causing a decrease, further, in the number of circulating erythrocytes and consequently causing a reduction of circulating hemoglobin. ${ }^{[7,9]}$ 
Comparison of Degree of Anemia with Stages of CKD: Our results show, at the level of severely impaired kidney function $\left(e G F R<15 \mathrm{ml} / \mathrm{min} / 1.73 \mathrm{~m}^{2}\right)$, anemia was frequently identified (57\%). This shows that as CKD progresses, anemia worsens in both diabetics as well as non-diabetics. This correlates with the study results of Hsu $\mathrm{CY}$ et al, Radtke HW et al and Chandra $\mathrm{M}$ et al..$^{[29-31]}$

Anemia Subtypes in Chronic Kidney Disease : Among CKD with anemia patients in our study, we observed normocytic in only 17 diabetics and 6 non-diabetics. Rest showed microcytic (28 in diabetics and 13 in non-diabetics) and macrocytic (5 in diabetics and 4 in non-diabetics) blood picture. This implies that factors other than CKD like nutritional (iron, B12) deficiency may play a role in anemia in both diabetics and non-diabetics. ${ }^{[32]}$

\section{Conclusion}

To summarize, a high incidence of anemia was observed in diabetics even without renal insufficiency. Furthermore majority of these anemic patients had microcytic blood picture with low iron profile which in turn indicates iron deficiency. This implies that causes other than CKD such as nutritional deficiency have a significant role in the development of anemia in diabetes. This contrast with the commonly presumed fact that the predominant risk factor for the development of anemia in a diabetic population has been found to be the presence of CKD. We also observed that severity of anemia worsens as CKD progresses. The prevalence of anemia was increased at depressed levels of eGFR in patients with poor controlled diabetics compared to controlled diabetics and non-diabetics. Hence in this study we insist on the utter importance of evaluating the causes of anemia other than CKD like nutritional (iron) deficiencies for accurate diagnosis, treatment and thereby preventing the prognosis of diabetic complications.

\section{Ethical Approval}

All procedures performed in studies involving human participants were in accordance with the ethical standards of the institutional and/or national research committee and with the 1964Helsinki declaration and its later amendments or comparable ethical standards.

\section{References}

1. Wright JA, Oddy MJ, Richards T. Presence and Characterisation of Anaemia in Diabetic Foot Ulceration. Anemia. 2014.

2. Bonakdaran S, Gharebaghi M, Vahedian M. Prevalence of anemia in type 2 diabetes and role of renal involvement. Saudi J KidneyDisTranspl. 2011;22:286-290.

3. Abate A, Birhan W, Alemu A. Association of anemia and renal function test among diabetes mellitus patients attending
Fenote Selam Hospital, West Gojam, Northwest Ethiopia: a cross sectional study. BMC Hematol. 2013;13:1.

4. Thomas MC, Cooper ME, Rossing K, Parving HH. Anaemia in diabetes: is there a rationale to TREAT?. Diabetologia. 2006;49:1151-7.

5. Jones SC, Smith D, Nag S, Bilous MT, Winship S, Wood A, Bilous RW. Prevalence and nature of anaemia in a prospective, population-based sample of people with diabetes: Teesside anaemia in diabetes (TAD) study. Diabet Med. 2010;27:655-9.

6. Al-Khoury S, Afzali B, Shah N, Covic A, Thomas S, Goldsmith DJ. Anaemia in diabetic patients with chronic kidney disease - prevalence and predictors. Diabetologia. 2006;49:1183-9.

7. El-Achkar TM, Ohmit SE, McCullough PA, Crook ED, Brown WW, Grimm R, et al. Kidney Early Evaluation Program: Higher prevalence of anemia with diabetes mellitus in moderate kidney insufficiency: The Kidney Early Evaluation Program. Kidney Int. 2005;67:1483-8.

8. Winkler AS, Marsden J, Chaudhuri KR, Hambley H, Watkins PJ. Erythropoietin depletion and anaemia in diabetes mellitus. Diabet med. 1999;16:813-9.

9. Bosman DR, Winkler AS, Marsden JT, Macdougall IC, Watkins PJ. Anemia with erythropoietin deficiency occurs early in diabetic nephropathy. Diabetes care. 2001;24:495-9.

10. Ishimura E, Nishizawa Y, Okuno S, Matsumoto N, Emoto $\mathrm{M}$, Inaba M, et al. Diabetes mellitus increases the severity of anemia in non-dialyzed patients with renal failure. J nephrol. 1997;11:83-6.

11. Beutler E, Waalen J. The definition of anemia: what is the lower limit of normal of the blood hemoglobin concentration?. Blood. 2006;107:1747-50.

12. Lam AP, Gundabolu K, Sridharan A, Jain R, Msaouel P, Chrysofakis G. Multiplicative interaction between mean corpuscular volume and red cell distribution width in predicting mortality of elderly patients with and without anemia. Am J hematol. 2013;88:E245-9.

13. Isakov E, Froom P, Henig C, Barak M. Anemia and estimated glomerular filtration rates. Ann Clin Lab Sci. 2014;44:419-24.

14. Liu X, Qiu X, Shi C, Huang H, Huang J, Li M. Modified glomerular filtration rate-estimating equations developed in asiatic population for chinese patients with type 2 diabetes. Int J Endocrinol. 2014.

15. Levey AS, Eckardt KU, Tsukamoto Y, Levin A, Coresh $\mathrm{J}$, Rossert J, et al.Definition and classification of chronic kidney disease: a position statement from Kidney Disease: Improving Global Outcomes (KDIGO). Kidney Int. 2005;67:2089-100.

16. Dikow R, Schwenger V, Schömig M, Ritz E. How should we manage anaemia in patients with diabetes?. Nephrol Dial Transplant. 2002;17:67-72.

17. Yun YS, Lee HC, Yoo NC, Song YD, Lim SK, Kim KR, et al. Reduced erythropoietin responsiveness to anemia in 
diabetic patients before advanced diabetic nephropathy. Diabetes res clin pract. 1999;46:223-9.

18. Biaggioni I, Robertson D, Krantz S, Jones M, Haile V. The anemia of primary autonomic failure and its reversal with recombinant erythropoietin. Ann Intern med. 1994;121:181-6.

19. Cawood TJ, Buckley U, Murray A. Prevalence of anemia in patients with diabetes mellitus. Ir J Med Sci 2006;175:25-27.

20. Thomas MC, MacIsaac RJ, Tsalamandris C, Molyneaux L, Goubina I, Fulcher G, et al. The burden of anaemia in type 2 diabetes and the role of nephropathy: a cross-sectional audit. Nephrol Dial Transplant. 2004;19:1792-7.

21. Adeoye S, Abraham S, Erlikh I, Sarfraz S, Borda T, Yeung L. Anaemia and Haemoglobin A1c level: Is there a case for redefining reference ranges and therapeutic goals?. BJMP. 2014;7:6

22. Naets JP, Wittek M. The mechanism of action of androgens on erythropoiesis. Ann N Y Acad Sci. 1968;149:366-76.

23. Holdsworth S, Atkins RC, De Kretser DM. The pituitarytesticular axis in men with chronic renal failure. N Engl J Med. 1977;296:1245-9.

24. Phillips GB, Tuck CH, Jing TY, Boden-Albala B, Lin IF, Dahodwala N, et al. Association of hyperandrogenemia and hyperestrogenemia with type 2 diabetes in Hispanic postmenopausal women. Diabetes care. 2000;23:74-9.

25. Inaba M, Okuno S, Kumeda Y, Yamada S, Imanishi Y, Tabata $\mathrm{T}$, et al. Glycated albumin is a better glycemic indicator than glycated hemoglobin values in hemodialysis patients with diabetes: effect of anemia and erythropoietin injection. J Am Soc Nephrol. 2007;18:896-903.

26. Chujo K, Shima K, Tada H, Oohashi T, Minakuchi J, Kawashima S. Indicators for blood glucose control in diabetics with end-stage chronic renal disease: $\mathrm{GHb}$ vs. glycated albumin (GA). J Med Invest. 2006;53:223-8.

27. Riveline JP, Teynie J, Belmouaz S, Franc S, Dardari D, Bauwens M, et al. Glycaemic control in type 2 diabetic patients on chronic haemodialysis: use of a continuous glucose monitoring system. Nephrol Dial Transplant. 2009;24:2866-71.

28. Vos FE, Schollum JB, Coulter CV, Manning PJ, Duffull SB, Walker RJ. Assessment of markers of glycaemic control in diabetic patients with chronic kidney disease using continuous glucose monitoring. Nephrol. 2012;17:182-8.

29. Hsu CY, Bates DW, Kuperman GJ, Curhan GC. Relationship between hematocrit and renal function in men and women. Kidney Int. 2001;59:725-31.

30. Radtke HW, Claussner A, Erbes PM, Scheuermann EH, Schoeppe W, Koch KM. Serum erythropoietin concentration in chronic renal failure: relationship to degree of anemia and excretory renal function. Blood. 1979;54:877-84.

31. Chandra M, Clemons GK, McVicar MI. Relation of serum erythropoietin levels to renal excretory function: evidence for lowered set point for erythropoietin production in chronic renal failure. J Pediatr. 1988;113:1015-21.

32. Bonomini M, Del Vecchio L, Sirolli V, Locatelli F. New treatment approaches for the anemia of CKD. Am J Kidney Dis. 2016;67:133-42.

*Corresponding author:

Dr. LAVANYA RAJAGOPAL, Door no. 902, B-Block, SRM Medical Staff Quarters, SRM Medical College Hospital and Research Centre, Kattankulathur, Pincode: 603203, Chennai (India)

Phone: +91 8754131339

Email: drrlavan@yahoo.co.in

Date of Submission : 06.06.2017

Date of Acceptance : 22.07.2017

Financial or other Competing Interests: None.

Date of Publication : 22.12.2017 